\title{
Influence of COVID-19 pandemic on paediatric dental attendance
}

\author{
Nilüfer Üstün ${ }^{1} \cdot$ Beyza Ballı Akgöl ${ }^{1} \cdot$ Merve Bayram $^{1}$ (iD \\ Received: 4 January 2021 / Accepted: 25 March 2021 / Published online: 30 March 2021 \\ (C) Springer-Verlag GmbH Germany, part of Springer Nature 2021
}

\begin{abstract}
Objectives This retrospective study aimed to evaluate the effect of COVID-19 pandemic on dental attendance and emergency/ non-emergency visits of children during the outbreak, compared to the same period of 2019.

Materials and methods Patients who visited the paediatric department clinic during the observed period were included in this study. The patient's demographic data, purpose of visit, and treatment type were evaluated retrospectively from patient examination records. The Pearson chi-square and $t$-tests were used for comprehensive statistical analysis.

Results A total of 1454 patient files (1184/270 cases from non-pandemic/pandemic period) were assessed. A significant reduction was found in aggregated emergency/non-emergency visits during the pandemic period $(p<0.01)$. During the pandemic, average daily visits for emergency dental care were observed to have a decrease to half of the non-pandemic period. Nonemergency routine dental visits have also exhibited a drastic decline. Severe dental pain due to pulpal inflammation and abscess/ swelling were the most frequently reported urgent dental complaints that patients applied to the paediatric dental clinic during the pandemic period.

Conclusion COVID-19 pandemic has a significant influence on patients' attendance to paediatric dental clinic. Therefore, concerning a potential post-pandemic increase in treatment demand, meticulous future planning and proper regulation of dental care should be provided for better oral health and children's quality of life.

Clinical relevance This study's importance is the observation of dramatically reduced number of patient visits during the pandemic period which may yield increased number of oral health-related complications in the long run.
\end{abstract}

Keywords COVID-19 $\cdot$ Dental attendance $\cdot$ Emergency dental care $\cdot$ Non-emergency dental care $\cdot$ Paediatric dentistry $\cdot$ Epidemics

\section{Introduction}

The coronavirus disease (COVID-19) has spread to many countries quickly and became a global problem affecting the whole world. On 11 March 2020, WHO has announced COVID-19 as a pandemic disease [1]. On the same day, the Ministry of Health of the Republic of Turkey declared the first COVID-19 case [2]. The first death related to COVID-19 was reported on 17 March 2020 [3]. During the early period of the

Merve Bayram

mbayram@medipol.edu.tr

Nilüfer Üstün

niluferavcu@gmail.com

Beyza Ballı Akgöl

bbakgol@medipol.edu.tr

1 School of Dentistry, Department of Pedodontics, Istanbul Medipol University, 34093 Istanbul, Turkey pandemic, recommendations for disease prevention as well as social distancing and local quarantine necessities were announced. Several further restrictions such as interruption of education, cancellation of public events were announced on 16 March 2020 [4].

Severe acute respiratory syndrome coronavirus 2 (SARSCoV-2) may be transmitted directly (cough, sneeze, and droplet inhalation) and by contact (contact with oral, nasal and eye mucosa) or by inhalation/ingestion of microorganisms in droplets/bioaerosols [5, 6]. It may also be transmitted directly or indirectly by the saliva [7]. Dental hospitals are vulnerable domains that are exposed to the COVID-19 virus, given the fact that droplet and aerosols are produced during practice. Furthermore, regular transmission routes such as speech, coughing, and sneezing also cause transmission by contact. Viral particles as well as small infected droplets in the air may cause through long-distance transmission between the patient and the dental staff $[5,8]$. These potential transmission routes resulted in patient anxiety, which affected the dental attendances, especially in emergency clinics [9-12]. On 16 
March 2020, American Dental Association (ADA) released a recommendation to postpone elective procedures as a measure to prevent the spread of COVID-19 [13]. With the coordination of faculty board, our department started to implement emergency treatment limitations on 16 March 2020. The initial emergency treatment limitations implemented by our department were as follows:

i. Severe dental pain due to pulpal and/or periodontal inflammation

ii. Abscess, cellulitis

iii. Acute, painful lesions/ulcerations of the oral mucosa

iv. Dento-alveolar trauma (tooth, jaw, facial fractures, tooth luxations and avulsions)

v. Uncontrolled haemorrhage

vi. Dental consultation required prior to medical procedures

vii. Snipping or adjustment of an orthodontic wire or appliances causing pain

Further emergency treatment limitations (based on the recommendations of Turkish Dental Association and the Ministry of Health) were implemented following the announcement of emergency procedures in dentistry by local authorities starting from 23 March 2020 [14]. The corresponding emergency treatment limitations were as follows:

i. Severe dental pain from pulpal inflammation

ii. Pericoronitis or third-molar pain

iii. Surgical post-operative osteitis, dry socket dressing changes

iv. Abscess or localized bacterial infection resulting in localized pain and swelling

v. Tooth fracture resulting in pain or causing soft tissue trauma

vi. Dental trauma with avulsion/luxation

vii. Jaw and facial fractures

viii. Acute, painful lesions/ulcerations of the oral mucosa

ix. Life-threatening or uncontrolled bleeding

$\mathrm{x}$. Intraoral/extraoral infections that threaten the patient's airway patency

xi. Treatment of patients who are receiving radiotherapy/ chemotherapy and/or who are planned to have organ transplants

xii. Patients who require dental consultation regarding medical problems

xiii. Suture removal

xiv. Denture adjustments or repairs when function impeded

$\mathrm{xv}$. Snipping or adjustment of an orthodontic wire or appliances

Local authorities recommended to postpone procedures other than the above-mentioned emergency definitions in private dental offices, all public and private dental clinics, hospitals, and universities until the mitigation stage that was proclaimed with a second order by the Ministry of Health. The measures were relieved during the mitigation stage which routine dental procedures could be provided.

Due to COVID-19 being a novel disease, there is limited data regarding the relative long-term impact, including the emergency and mitigation stage, on paediatric dental care. This study aims to assess the effect of COVID-19 pandemic on attendance and treatment requirements in the paediatric dental clinic during the outbreak. The study hypothesis was that COVID-19 pandemic has significant influence on patients' attendance to paediatric dental clinic. Dental practice in this study was conducted in the university clinic which provides emergency and comprehensive dental care for patients in routine basis. However, a strict protocol was applied during the COVID-19 outbreak, and only emergency treatments could be carried out during the 16 March 2020 to 1 June 2020.

\section{Materials and methods}

Data was obtained from the electronic patient records, following the ethics committee approval, for the periods between March 2019-June 2019 and March 2020-June 2020. All the clinical records included in the study had informed consent forms approved by the patients' parents, and the patients' personal information was kept confidential.

Patients who applied for and received dental care in the paediatric clinic between 16 March and 30 June of years 2019 and 2020 were included in this study. Dental problems could be solved with treatment under GA (during the study periods in 2019, 64 cases; in 2020, 8 cases) which the evaluations were conducted in a different zone of the hospital and by consultation, i.e., on telephone were excluded for analysis in this study.

The patients' demographic data (age, gender, health status), purpose of visits, and treatment types were recorded. The purpose of visits was assigned in classes of dental emergencies, urgent dental care, and dental non-emergency care based on ADA guidelines [15]. Dental emergency was categorized under three sub-classes by ADA as follows:

\section{i. Dental emergencies \\ ii. Urgent dental care \\ iii. Other urgent dental care}

Dental emergencies were defined as potentially lifethreatening and requiring immediate treatment to stop worsening health conditions, such as uncontrolled bleeding and airway obstruction. Urgent dental care was explained as focusing on the management of conditions that require 
immediate attention to relieve pain and/or reduce the risk of infection and alleviate the burden on hospital emergency departments. On the other hand, dental non-emergency had been limited as routine or non-urgent dental procedures in the concerning guidance [15].

\section{Patient evaluation and treatment protocol during COVID-19 outbreak}

Primarily, body temperature of the patient (and guard$\operatorname{ian}(\mathrm{s}))$ was measured in the waiting room before entering the dental office. A detailed anamnesis was taken with questioning risk history, i.e., COVID-19 symptoms present, and contact with a confirmed or suspected COVID-19 case. Oral examination was performed using a mirror and a probe combined with a panoramic radiography. Two paediatric dentists (BBA and NU) prioritized the cases by emergency status during the COVID-19 period. Following the prioritization, the cases were scheduled for treatment (urgent care or day scheduling) or registered on a non-emergent waiting list. Parents were kindly requested to leave for the waiting room. Pre-procedural mouth-rinse with $0.2 \%$ povidone-iodine was used in children who are able to spit. Treatment procedures were carried out with primary protection such as work cloth, shoe cover, disposable cap, N95 mask, face shield, and disposable latex gloves. Following each case's management, the dental office environment was well ventilated and disinfected based on WHO recommendations [16].

\section{Retrospective data acquisition}

Patients were identified by a patient protocol number and case number generated from database records, to protect confidentiality. The case number, age (at the time of the dental attendance), gender, health status, and attendance history of the patient were recorded.

All data was collected and evaluated by one independent examiner (MB). Dental emergency was evaluated as urgent (ADA sub-class ii) and other urgent dental care (ADA sub-class iii), due to the fact that no dental emergencies (ADA sub-class $i)$ application was observed during the study period. The treatment procedures were recorded as oral examination, oral prophylaxis, fissure sealant, fluoride therapy, restorative therapy, pulpotomy, pulpectomy, tooth extraction, space maintainers, basic orthodontic appliance, and prosthetic rehabilitation in a spreadsheet. Type of treatment data was extracted from the file. The state of the pandemic emergency period covered in this research was between 16 March and 1 June 2020; and the mitigation stage period was between 1 June and 30 June 2020 during the COVID-19 pandemic.

\section{Statistics}

Raw patient data extracted from the hospital database was structured using Microsoft Excel (Microsoft Corporation, Redmond, WA, USA) for further analysis. SPSS software version 25 (IBM Corporation, Armonk, NY, USA) was used to carry out statistical inference and generate corresponding figures: Pearson chi-square and independent samples $t$-test. The significance level was set as $<0.01$.

\section{Results}

A sum of 1454 case records who attended the paediatric department clinic during the pandemic and non-pandemic period $(270,1184$, respectively) were analysed in this retrospective study. Demographic data including age groups, gender, and health status was laid out in Table 1 . The age range was 1-14 years old with the mean of $7.75( \pm 2.60)$ years.

Comparison of the emergency and non-emergency visits is laid out in Fig. 1. A significant reduction was found in both emergency/non-emergency total visits during the pandemic period $(p<0.01)$. Mean daily visits within the study group were demonstrated in Table 2 . There was a statistically significant decline in the mean daily emergency/non-emergency visits during the pandemic period (Table $2, p<0.01$ ). During the pandemic, average daily visits for emergency dental care were observed to have a decrease to half of the nonpandemic period. Non-emergency routine dental visits have also exhibited a drastic decline.

The figures of dental attendance reasons, including the most frequently performed treatment types during the pandemic and non-pandemic periods, were laid out in Table 3. According to the test results, "severe dental pain from pulpal inflammation" and "abscess, localized pain and swelling" were the most frequently observed urgent problems both in

Table 1 Demographic data

\begin{tabular}{|c|c|c|c|c|}
\hline & \multicolumn{2}{|c|}{ Non-pandemic period } & \multicolumn{2}{|c|}{ Pandemic period } \\
\hline & $n$ & $\%$ & $n$ & $\%$ \\
\hline \multicolumn{5}{|l|}{ Age groups } \\
\hline $0 \leq 6$ years & 305 & 25.8 & 67 & 24.8 \\
\hline $6-14$ years & 879 & 74.2 & 203 & 75.2 \\
\hline \multicolumn{5}{|l|}{ Gender } \\
\hline Male & 636 & 53.7 & 143 & 53 \\
\hline Female & 548 & 46.3 & 127 & 47 \\
\hline \multicolumn{5}{|l|}{ Health Status } \\
\hline Healthy child & 1140 & 96.3 & 252 & 93.3 \\
\hline Child with systemic disease & 44 & 3.7 & 18 & 6.7 \\
\hline
\end{tabular}




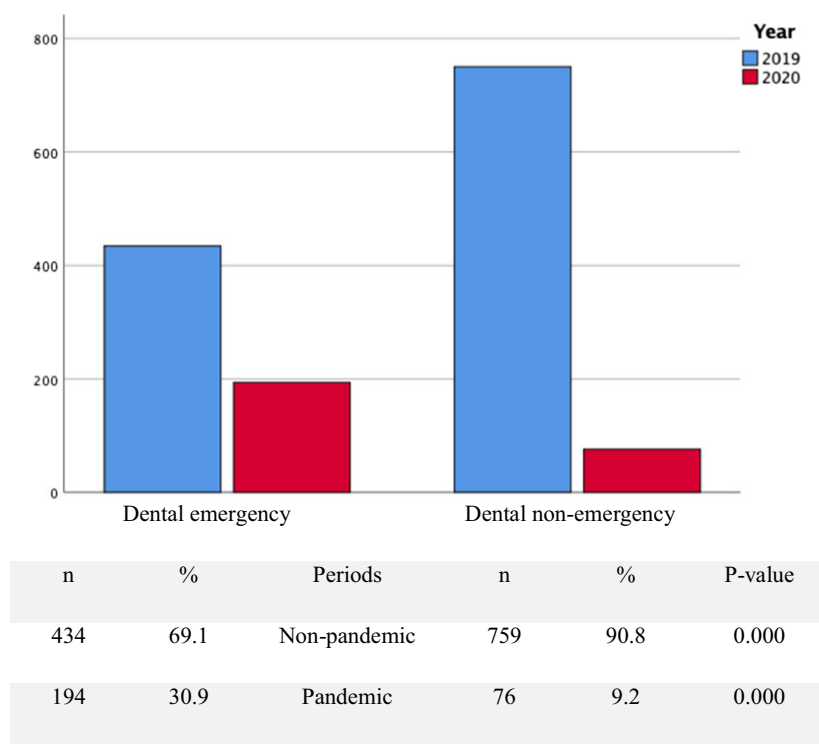

Fig. 1 Dental emergency/non-emergency dental care total visits during non-pandemic and pandemic periods

non-pandemic and pandemic periods, and there was a statistically significant difference between two periods $(p<0.01)$. The number of dental visits for the $0 \leq 6$ years old age group with severe dental pain from pulpal inflammation was observed more than the older age group, and this difference was found statistically significant $(p<0.01)$. Although "snipping or adjustments of an orthodontic wire/appliances" visits in other emergencies had shown a statistically significant increase $(p<0.01)$, "initial/periodic oral examinations and recall visits", "orthodontic procedures", and "restorative dentistry" visits in dental non-emergency care group had shown a statistically significant decline during the pandemic period $(p<$ $0.01)$.

Table 4 represents the types of treatment procedures during the study period. Oral examination, tooth extraction, and other procedures (cementation, repairment, snipping) had demonstrated an upward trend during the pandemic period.

Figure 2 showed the weekly patient visits during nonpandemic and pandemic period.

\section{Discussion}

This retrospective study analysed the child patients' dental care visits from 16 March 2020 to 30 June 2020 and compared the results with the same period of 2019. There is limited research that analysed attendance in the paediatric dental setting during the COVID-19 pandemic. The presented data yields valuable outputs regarding the emergency/nonemergency dental visits to the paediatric dental clinic.

COVID-19 has been diagnosed as a novel disease recently. Therefore, data throughout the literature was limited to a short time span. Sixteen weeks study period and large sample size are the strengths of this study. Moreover, having a mitigation stage as well as the emergency stage during the study period added novelty.

To make a decision on what situation was an emergency (or non-emergency), parents were able to reach the clinicians by telephone, especially during the pandemic period. Nonemergency situations were postponed to forthcoming dates. These consultations were not recorded to the electronic patient file, which may have an effect on the results. This was considered as a limitation of the study.

A recently published study [9] in China evaluated the impact of current COVID-19 outbreak on the utilization of emergency dental services. Test period covered 1-10 February 2020 , control period was $1-10$ January 2020 , and the number of patients attended to the dental emergency service was reported to have decreased by $38 \%$ following the onset of the COVID-19 epidemic. The present study reports an identical result of a $38 \%$ reduction in emergency dental visits to paediatric clinic during the pandemic period (Fig. 1). The study period covers a temporary suspension of routine dental care (11 weeks) in the dental clinics, plus a mitigation stage (5 weeks). Although the study period was extended further than the aforementioned research [9], including the normalization period, a relatively stable decrease in dental clinic visits was observed, which may be related to ongoing fear and anxiety due to ambiguity.

While the mean emergency dental care visits decreased to half of the non-pandemic period, dental non-emergency visits decreased to one-tenth (Table 2), these results were statistically significant $(p<0.01)$. Compared to the previously reported results [9], a sharper decline in the number of dental nonemergency visits was observed. The differences could be attributed to the longer time of our study period. Moreover, nonemergency or routine dental procedures could be provided only during the mitigation stage of the pandemic period, which explains the drastic reduction of the visits during the non-pandemic period. There was an $81.6 \%$ drop in the overall dental non-emergency visits in the paediatric dental clinic (Fig. 1).
Table 2 Comparison of the emergency/non-emergency mean daily visits during non-pandemic and pandemic periods

\begin{tabular}{llll}
\hline Purpose of visit & $\begin{array}{l}\text { Non-pandemic period } \\
\text { mean } \pm \text { SD }\end{array}$ & $\begin{array}{l}\text { Pandemic period } \\
\text { mean } \pm \text { SD }\end{array}$ & $p$ Value \\
\hline Dental emergency visit & $4.93 \pm 3.51$ & $2.08 \pm 3.09$ & 0.000 \\
Dental non-emergency visit & $8.50 \pm 4.44$ & $0.91 \pm 1.77$ & 0.000 \\
\hline
\end{tabular}


Table 3 Comparison of the urgent dental care, other urgent dental care and dental non-emergency care visits, including the most frequently performed treatment types

\begin{tabular}{|c|c|c|c|c|c|}
\hline \multirow[t]{2}{*}{ Purpose of visit* } & \multirow{2}{*}{$\begin{array}{l}\text { Non-pandemic } \\
\text { period } n(\%)\end{array}$} & \multirow{2}{*}{$\begin{array}{l}\text { Pandemic } \\
\text { period } n(\%)\end{array}$} & \multirow{2}{*}{$\begin{array}{l}p \\
\text { Value }\end{array}$} & \multicolumn{2}{|c|}{ Most frequently performed treatments } \\
\hline & & & & 2019 & 2020 \\
\hline \multicolumn{6}{|l|}{ Urgent dental care visits } \\
\hline Severe dental pain from pulpal inflammation & $58(4.64)$ & $45(15.96)$ & 0.000 & Oral examination/pulpectomy & Oral examination/extraction \\
\hline Abscess, localized pain and swelling & $47(3.76)$ & $34(12.06)$ & 0.000 & $\begin{array}{l}\text { Oral examination/ pulpectomy/- } \\
\text { extraction }\end{array}$ & Oral examination/extraction \\
\hline $\begin{array}{l}\text { Tooth fracture resulting in pain or causing soft } \\
\text { tissue trauma }\end{array}$ & $3(0.24)$ & $0(0)$ & 0.408 & Restorative therapy & - \\
\hline Dental trauma with avulsion/luxation & $2(0.16)$ & $3(1.06)$ & 0.017 & Extraction & Oral examination \\
\hline \multicolumn{6}{|l|}{ Other urgent dental care visits } \\
\hline $\begin{array}{l}\text { Extensive caries or defective restorations } \\
\text { causing pain }\end{array}$ & $300(24)$ & $82(29.08)$ & 0.090 & Oral examination/pulpotomy & Oral examination/extraction \\
\hline Suture removal & $0(0)$ & $1(0.35)$ & 0.036 & - & - \\
\hline $\begin{array}{l}\text { Replacing temporary filling on endo access } \\
\text { openings in patients experiencing pain }\end{array}$ & $19(1.52)$ & $9(3.19)$ & 0.062 & Restorative therapy & Restorative therapy \\
\hline $\begin{array}{l}\text { Snipping or adjustments of an orthodontic } \\
\text { wire or appliances }\end{array}$ & $2(0.16)$ & $18(6.38)$ & 0.000 & Others & Others \\
\hline Ulcerating the oral mucosa & $4(0.32)$ & $2(0.71)$ & 0.351 & - & - \\
\hline \multicolumn{6}{|l|}{ Dental non-emergency care visits } \\
\hline $\begin{array}{l}\text { Initial/periodic oral examinations and recall } \\
\text { visits, including routine radiographs }\end{array}$ & $347(27.76)$ & $28(9.93)$ & 0.000 & Oral examination & Oral examination \\
\hline $\begin{array}{l}\text { Routine dental cleaning and preventive } \\
\text { therapies }\end{array}$ & $76(6.08)$ & $8(2.84)$ & 0.028 & $\begin{array}{l}\text { Oral prophylaxis/fissure sealant } \\
\text { application/fluoride therapy }\end{array}$ & $\begin{array}{l}\text { Oral prophylaxis/fissure } \\
\text { sealant application/ }\end{array}$ \\
\hline $\begin{array}{l}\text { Orthodontic procedures other than those to } \\
\text { address acute issues }\end{array}$ & $91(7.28)$ & $3(1.06)$ & 0.000 & $\begin{array}{l}\text { Space maintainers/basic ortho- } \\
\text { dontic appliances }\end{array}$ & Oral examination \\
\hline Extraction of asymptomatic teeth & $48(3.84)$ & $14(4.96)$ & 0.406 & Extraction & Extraction \\
\hline $\begin{array}{l}\text { Restorative dentistry including treatment of } \\
\text { asymptomatic carious lesions }\end{array}$ & $243(19.44)$ & $31(10.99)$ & 0.001 & Restorative therapy & Restorative therapy \\
\hline Aesthetic dental procedures & $10(0.8)$ & $4(1.42)$ & 0.334 & Restorative therapy & Restorative therapy \\
\hline
\end{tabular}

*Based on ADA guidelines [15]

Severe dental pain from pulpal inflammation (\% 15.96) and abscess/localized pain and swelling (\% 12.06) were the most frequent reason for child patients' urgent dental care attendance during the pandemic period, as well as during
Table 4 Comparison of the performed total treatment procedures during non-pandemic and pandemic period

\begin{tabular}{lll}
\hline Treatment procedure & $\begin{array}{l}\text { Non-pandemic period } \\
n(\%)\end{array}$ & $\begin{array}{l}\text { Pandemic period } \\
n(\%)\end{array}$ \\
\hline Oral examination & $622(36.85)$ & $137(39.03)$ \\
Oral prophylaxis & $43(2.55)$ & $5(1.42)$ \\
Fissure sealant & $153(9.06)$ & $10(2.85)$ \\
Fluoride therapy & $4(0.24)$ & $0(0)$ \\
Restorative therapy & $460(27.25)$ & $70(19.94)$ \\
Pulpotomy & $160(9.48)$ & $31(8.83)$ \\
Pulpectomy & $31(1.84)$ & $7(1.99)$ \\
Tooth extraction & $124(7.35)$ & $67(19.09)$ \\
Space maintainers & $45(2.67)$ & $2(0.57)$ \\
Basic orthodontic appliance & $7(0.41)$ & $0(0)$ \\
Prosthetic rehabilitation & $0(0)$ & $0(0)$ \\
Others (cementation, repairment, snipping, etc.) & $39(2.31)$ & $22(6.27)$ \\
\hline
\end{tabular}




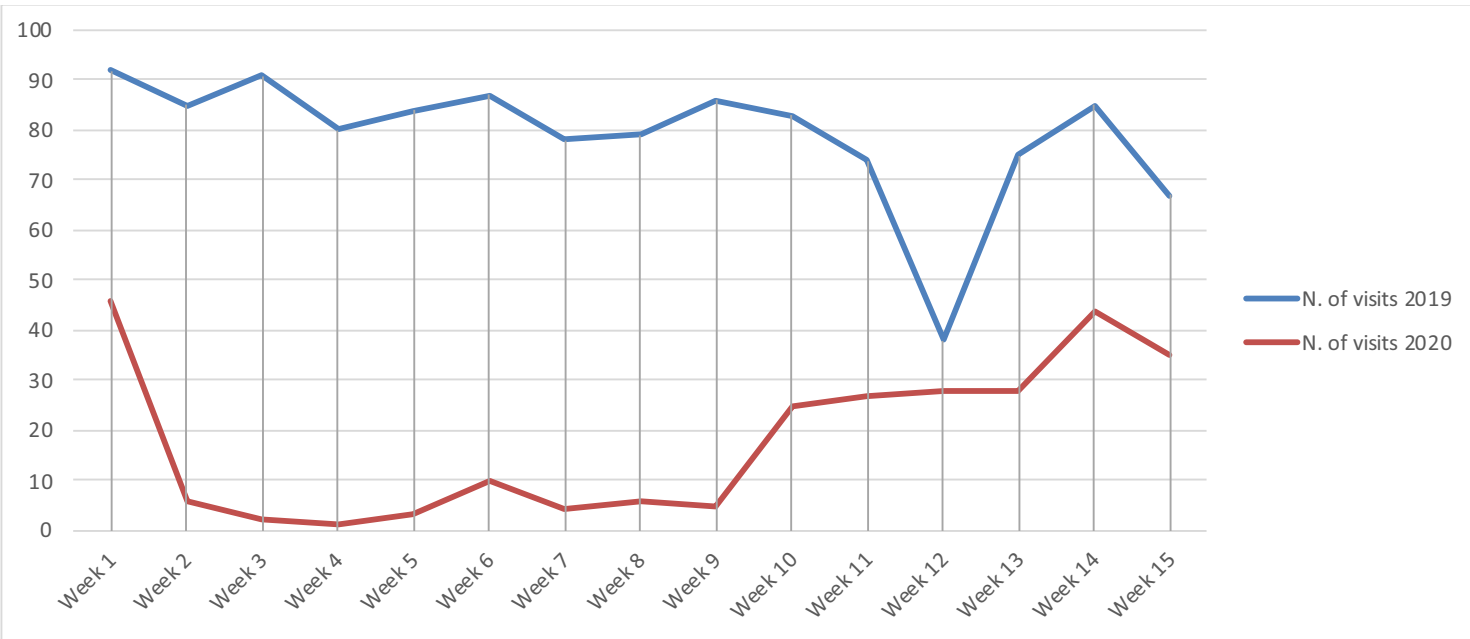

Fig. 2 Weekly patient visits to the paediatric dentistry clinic during non-pandemic and pandemic periods

non-pandemic period, whereas visits regarding dental trauma were low. Our findings are in-line with previous researchers reporting dental pain from pulpal inflammation, abscess, or swelling as the most common reason for patients seeking treatment $[9,10,17-19]$. Although pulpectomy was situated as management of signs and symptoms related to dental pain and abscess/swelling during the non-pandemic period, extraction was preferred to refrain from the high risk of aerosols (Table 3). Implementing alternative treatment choices during COVID-19 pandemic will potentially have some consequences; hence dental professionals should provide additional information to parents regarding space management and suggest strongly the use of space maintainers when extraction was chosen instead of pulpectomy.

A minor increase was observed in other emergency dental care visits during the pandemic period except the reason of referral: "snipping or adjustments of an orthodontic wire/appliances." There was a significant difference in this referral reason $(p<0.01)$, which may be explained by the patients' choices to not interrupt the treatment and proceed with the non-aerosol generating treatment procedure and short processing time.

The dental non-emergency care visit reasons: "Initial/periodic oral examinations and recall visits", "orthodontic procedures", "restorative dentistry" were less common in pandemic period compared to the non-pandemic period (Table 3, $p<$ 0.01 ). As routine dental care was not recommended during the COVID-19 acute phase [20], we could only provide nonemergency procedures in the mitigation stage period (5 weeks). Pulpotomy, pulpectomy, restorative therapy, and oral prophylaxis were not the first-choice procedures due to their characteristics of aerosol generation.

A recent article [19] retrospectively analysed children's dental health during COVID-19 via online consultation system. Dental pain consultations were found significantly higher in the 3-6 years old group compared to the other age groups.
Preschool-age children are more prone to early childhood caries (ECC), which causes severe dental pain and requires urgent dental management. ECC is one of the most common chronic diseases in pre-school children and affects both families and children's quality of life due to dental pain [21]. Similar to the research mentioned above [19], $0 \leq 6$ years age group attended to the paediatric dental clinic with severe dental pain more than the older age group during COVID-19. In spite of the pandemic derived fear and anxiety existence in parents, children are willing to seek urgent dental care when suffering from severe toothache.

Weekly child patient attendances may be viewed in Fig. 2 . The reason of the sharp decline observed in week 12 despite the steady trend during 2019 was the national holiday season (4-6 June 2019). The same holiday season in 2020 was between 24 and 26 May. A dramatic drop can be observed in weekly number of patient visits during the pandemic period. Although one may view the reported figures solely as a significant decline in numbers between two important time frames, it is more than a downward trend. It is crucial to consider what this dramatic decline may yield in the long run, in terms of oral health-related complications. Hence, further prospective studies may focus on the long-term impact of COVID-19 on oral health in the general population.

\section{Conclusion}

Suspension of routine dental care may cause an increased dental treatment requirement of child patients during the post-pandemic period. Therefore, concerning a potential post-pandemic increase in treatment demand, meticulous future planning and proper regulation of dental care should be provided for better oral health and children's quality of life. Local health authorities should designate prevention strategies with consultation to dental professionals. Future dental 
treatment needs of the child patients may be predicted using the yielded robust results of this research. This study successfully concluded that COVID-19 pandemic has a significant influence on dental attendances in the paediatric clinic.

Acknowledgements We thank our patients who participated in the study.

Author contribution NU conceptualized the manuscript. BBA and NU carried out methodology; MB carried out data analysis, drafted and edited the manuscript. All authors subsequently revised the drafts. All authors read and approved the final manuscript.

\section{Declarations}

Ethics approval Ethics committee approval was received for this study from the Ethics Committee of Istanbul Medipol University (REF: E-10840098-772.02-66610).

Informed consent Informed consent was obtained from parents of all participants included in the study.

Conflict of interest The authors declare no competing interests.

\section{References}

1. WHO (2020) WHO Director-General's opening remarks at the mission briefing on COVID-19. [Online]. Available from: https:// www.who.int/dg/speeches/detail/who-director-general-s-openingremarks-at-the-mission-briefing-on-covid-19 [Accessed on 1st March 2020]. In: https://www.who.int/dg/speeches/detail/whodirector-general-s-opening-remarks-at-the-media-briefing-oncovid-19\%2D\%2D-11-march-2020

2. T.C. Sağlık Bakanlığ 1 COVID-19 (SARS-CoV-2 Enfeksiyonu) Rehberi

3. T.C. Sağlık Bakanlı̆̆ Genel Koronavirüs Tablosu. https://covid19. saglik.gov.tr/TR-66935/genel-koronavirus-tablosu.html. Accessed 21 Dec 2020

4. Erdem İ (2020) Koronavirüse (Covid-19) Karș1 Türkiye'nin Karantina ve Tedbir Politikaları. J Turkish Stud 15:377-388. https://doi.org/10.7827/TurkishStudies.43703

5. Peng X, Xu X, Li Y, Cheng L, Zhou X, Ren B (2020) Transmission routes of 2019-nCoV and controls in dental practice. Int J Oral Sci 12. https://doi.org/10.1038/s41368-020-0075-9

6. Lu C, Liu X, Jia Z (2020) 2019-nCoV transmission through the ocular surface must not be ignored. Lancet 395:e39. https://doi. org/10.1016/S0140-6736(20)30313-5

7. Belser JA, Rota PA, Tumpey TM (2013) Ocular tropism of respiratory viruses. Microbiol Mol Biol Rev 77:144-156. https://doi.org/ 10.1128/mmbr.00058-12

8. Xie X, Li Y, Sun H, Liu L (2009) Exhaled droplets due to talking and coughing. J R Soc Interface 6:S703-S714. https://doi.org/10. 1098/rsif.2009.0388.focus
9. Guo H, Zhou Y, Liu X, Tan J (2020) The impact of the COVID-19 epidemic on the utilization of emergency dental services. J Dent Sci. 15:564-567. https://doi.org/10.1016/j.jds.2020.02.002

10. Petrescu NB, Aghiorghiesei O, Mesaros AS, Lucaciu OP, Dinu CM, Campian RS, Negucioiu M (2020) Impact of COVID-19 on dental emergency services in Cluj-Napoca metropolitan area: A cross-sectional study. Int J Environ Res Public Health 17:7716. https://doi.org/10.3390/ijerph17217716

11. Bai J, Xu T, Ji A-P, Sun W, Huang MW (2020) Impact of COVID19 on oral emergency services. Int Dent J. 71:27-31. https://doi.org/ 10.1111/idj.12603

12. Long L, Corsar K (2020) The COVID-19 effect: number of patients presenting to The Mid Yorkshire Hospitals OMFS team with dental infections before and during The COVID-19 outbreak. Br J Oral Maxillofac Surg 58:713-714. https://doi.org/10.1016/j.bjoms. 2020.04 .030

13. ADA recommending dentists postpone elective procedures. https:// www.ada.org/en/publications/ada-news/2020-archive/march/adarecommending-dentists-postpone-elective-procedures. Accessed 21 Dec 2020

14. (2020) Türk Dişhekimleri Birliği. http://www.tdb.org.tr/icerik goster.php?Id=3427. Accessed 31 Dec 2020

15. American Dental Association What constitutes a dental emergency? https://success.ada.org/ /media/CPS/Files/OpenFiles/ ADA_COVID19_Dental_Emergency_DDS.pdf. Accessed 20 Dec 2020

16. WHO (2020) Cleaning and disinfection of environmental surfaces in the context of COVID-19. https://www.who.int/publications/i/ item/cleaning-and-disinfection-of-environmental-surfaces-inthecontext-of-covid-19. Accessed 30 Dec 2020

17. Carter E, Currie CC, Asuni A, Goldsmith R, Toon G, Horridge C, Simpson S, Donnell C, Greenwood M, Walton G, Cole B, Durham J, Holliday R (2020) The first six weeks - setting up a UK urgent dental care centre during the COVID-19 pandemic. Br Dent J 228: 842-848. https://doi.org/10.1038/s41415-020-1708-2

18. Grossman S, Sandhu P, Sproat C, Patel V (2020) Provision of dental services at a single institution in the UK's epicentre during the COVID-19 pandemic. Br Dent J 228:964-970. https://doi.org/ 10.1038/s41415-020-1716-2

19. Yang F, Yu L, Qin D, Hua F, Song G (2021) Online consultation and emergency management in paediatric dentistry during the COVID-19 epidemic in Wuhan: a retrospective study. Int J Paediatr Dent 31:5-11. https://doi.org/10.1111/ipd.12722

20. Wang Y, Zhou C-C, Shu R, Zou J (2020) Oral health management of children during the epidemic period of coronavirus disease 2019. J Sichuan Univ (Medical Sci Ed) 51:151-154. https://doi.org/10. 12182/20200360101

21. Pahel BT, Rozier RG, Slade GD (2007) Parental perceptions of children's oral health: the early childhood oral health impact scale (ECOHIS). Health Qual Life Outcomes 5:6. https://doi.org/10. $1186 / 1477-7525-5-6$

Publisher's note Springer Nature remains neutral with regard to jurisdictional claims in published maps and institutional affiliations. 